\title{
Out-of-pocket costs and adherence to antihypertensive agents among older adults covered by the public drug insurance plan in Quebec
}

\author{
This article was published in the following Dove Press journal: \\ Patient Preference and Adherence \\ 8 September 2017 \\ Number of times this article has been viewed
}

\author{
Raymond Milan' \\ Helen-Maria Vasiliadis ${ }^{2,3}$ \\ Samantha Gontijo Guerra' \\ Djamal Berbiche ${ }^{3}$ \\ 'Health Sciences Program, Faculty \\ of Medicine and Health Sciences, \\ Université de Sherbrooke, \\ ${ }^{2}$ Department of Community Health \\ Sciences, Faculty of Medicine and \\ Health Sciences, Université de \\ Sherbrooke, Sherbrooke, ${ }^{3}$ Charles-Le \\ Moyne Hospital Research Center, \\ Longueuil, QC, Canada
}

Objective: To evaluate the effect of patient out-of-pocket costs on adherence to antihypertensive agents (AHA) in community-dwelling older adults covered by the public drug insurance plan in Quebec.

Methods: This is a secondary analysis of data from the "Étude sur la santé des aînés" study (2005-2008) on community-dwelling older adults in Quebec aged 65 years and older $(\mathrm{N}=2,811)$. The final sample included 881 participants diagnosed with arterial hypertension and treated with AHA. Medication adherence was measured with the proportion of days covered over a 2-year follow-up period ( $<80 \%$ and $\geq 80 \%$ ). Out-of-pocket costs for AHA, in Canadian dollars (CAD), at cohort entry were categorized as follows: $\$ 0, \$ 0.01-\$ 5.00, \$ 5.01-\$ 10.00, \$ 10.01-\$ 15.00$ and \$15.01-\$36.00. Multivariable logistic regression models were constructed to study adherence to AHA as a function of out-of-pocket costs while controlling for several confounders. Models were also stratified by annual household income ( $<\$ 15,000 \mathrm{CAD}$ and $\geq \$ 15,000 \mathrm{CAD})$.

Results: In this study, $80.8 \%$ of participants were adherent to their AHA. Among participants reporting an annual household income $<\$ 15,000 \mathrm{CAD}$, those with an out-of-pocket cost of \$10.01-\$15.00 CAD were significantly less adherent to their AHA than those with no contribution $(\mathrm{OR}=0.175,95 \% \mathrm{CI}: 0.042-0.740)$. Among participants reporting an income of $\geq \$ 15,000$ CAD, those with out-of-pocket costs of $\$ 0.01-\$ 5.00$ CAD (OR $=0.194 ; 95 \%$ CI: 0.048-0.787), $\$ 5.01-\$ 10.00 \mathrm{CAD}(\mathrm{OR}=0.146 ; 95 \% \mathrm{CI}: 0.036-0.589), \$ 10.01-\$ 15.00 \mathrm{CAD}(\mathrm{OR}=0.192$; 95\% CI: $0.047-0.777$ ) and $\$ 15.01-\$ 36.00 \mathrm{CAD}(\mathrm{OR}=0.160,95 \%$ CI: $0.039-0.655$ ) were significantly less adherent to their AHA than participants with no contribution.

Conclusion: Increased out-of-pocket costs are associated with non-adherence to AHA in older adults covered by a public drug insurance plan, more importantly in those reporting an annual household income $\geq \$ 15,000 \mathrm{CAD}$. A reduction in the amount of out-of-pocket costs and yearly maximum contribution for drugs may improve adherence to treatment.

Keywords: medication adherence, seniors, hypertension, out-of-pocket costs, income

\section{Introduction}

Of all chronic conditions, cardiovascular diseases are the second leading cause of death $^{1}$ with hypertension, the most prevalent, affecting $65 \%$ of older adults in Canada. ${ }^{2}$ Adherence to treatment regimens contributes significantly to increase patient life expectancy and improve clinical outcomes. ${ }^{3}$ In contrast, non-adherence to antihypertensive agents (AHA), mainly associated with uncontrolled blood pressure, can lead to longterm cardiovascular complications, ${ }^{4-6}$ increased health system $\operatorname{costs}^{7-11}$ and a poor
Correspondence: Raymond Milan Université de Sherbrooke - Campus de Longueuil, 150 Place Charles-Le Moyne, Longueuil, QC J4K 0A8, Canada

Tel + I 4504665000 ext 386I

Email raymond.milan@usherbrooke.ca 
quality of life. ${ }^{12}$ Depending on the method used, adherence to AHA ranges between $16 \%$ and $77 \%{ }^{13}$

The introduction of health system factors such as deductibles and coinsurance by Quebec's public drug policy in 1997 for prescription drugs was associated with a decrease in drug use among older adults. ${ }^{14}$ A number of subsequent studies in the USA ${ }^{15-19}$ and Canada $^{20}$ also highlighted an association between patient out-of-pocket costs and adherence rates to AHA. The studies conducted in the USA were consistent and included participants covered by the Veteran Affairs, ${ }^{15}$ Medicare, ${ }^{16}$ Medicaid, ${ }^{16,17}$ and private insurance plans. ${ }^{18,19}$ The studies reported a significant decrease in adherence to AHA, with an average increase of 5 dollars and more in outof-pocket costs for medications. ${ }^{15-20}$ Others have also shown that participants with low household incomes are at a greater risk of non-adherence due to drug costs. ${ }^{21-23}$ Results from a telephone survey across Canada showed that respondents in the lowest household income quintile were 3.3 times more likely to report cost-related non-adherence than those with higher household incomes. ${ }^{23}$

More recently, in an older adult population with hypertension, Kratzer et al looked into the effect of public vs private drug coverage on the use of AHA in Ontario and did not find a difference. ${ }^{24}$ Given that drug coverage policies differ by province, these results are difficult to extrapolate. Further, results from studies conducted in the USA are not readily generalizable to Canada, given its universal health care system and the different policies on drug coverage and reimbursement. ${ }^{21,25-29}$

The purpose of this study was to evaluate the effect of patient out-of-pocket costs on adherence to AHA in community-dwelling older adults covered by Quebec's public drug insurance plan while also studying the effect of income, to better ascertain the influence of socio-economic factors on adherence regimens.

\section{Methods}

\section{Public drug insurance plan of Quebec}

In 1997, the Quebec government implemented the universal drug insurance program, which ensured that residents would be covered either under a private or the public drug insurance plan with "Régie de l'Assurance Maladie du Québec" (RAMQ), Quebec's medical insurance plan. As for the implementation of the drug policy, residents covered by the RAMQ had to pay a deductible, coinsurance and an annual premium based on the annual household income, instead of the usual copayment of \$2 CAD for each prescription delivered. For residents aged 65 years and older, the out-of-pocket costs (deductibles + coinsurance) for medications are based on the guaranteed income supplement (GIS). The GIS is an amount based on the annual household income and added monthly to an individual's pension. ${ }^{30}$ The lower the income, the higher the GIS. From 2005 to 2008, the deductible fee in the RAMQ ranged from $\$ 0 \mathrm{CAD}$ to $\$ 14.10 \mathrm{CAD}$ and the coinsurance ranged from $0 \%$ to $30 \%$ per month. After reaching a yearly maximum contribution that varies between \$200 CAD and \$904 CAD, depending on the GIS, individuals receive their medications without additional out-of-pocket costs. It should be noted that as of July 1, 2005, older adults with a maximum GIS (100\%) were exempted from out-of-pocket costs. Those with a GIS between $94 \%$ and $99 \%$ were also exempted as of July 1, 2007. Senior residents with a GIS <94\% had to pay out-of-pocket costs. ${ }^{30}$ An example of how out-of-pocket costs are computed from a monthly prescription is presented in Table 1 . In 2010, 33\% of residents covered by the RAMQ were older adults, and they accounted for $58 \%$ of the total cost of pharmaceutical services in the province. ${ }^{31}$

\section{Study design}

Data used in the study came from the longitudinal Quebec survey on Senior's Health "Étude sur la santé des aînés" (ESA) conducted between 2005 and 2008, which included French-speaking community-dwelling adults aged 65 years and older $(\mathrm{N}=2,811)$. Random-digit dialing was used to select participants. The sampling frame was stratified according to geographic areas (metropolitan, urban and rural). A proportional sample was recruited according to Quebec's 16 health administrative regions. People living in northern regions in Quebec were not included due to feasibility issues. One older adult was

Table I An example of how out-of-pocket costs are computed from a $\$ 60$ CAD prescription filled between January I and June 30, 2006

\begin{tabular}{lll}
\hline & $\begin{array}{l}\text { Deductible per } \\
\text { month (CAD) }\end{array}$ & $\begin{array}{l}\text { Coinsurance per } \\
\text { month (\%) }\end{array}$ \\
\hline Participants with a low income & 8.33 & $25 \%$ \\
${\text { (ie, GIS between } 94 \% \text { and } 99 \%)^{\mathrm{a}}}_{\text {Participants with a high income }}$ & $60-8.33=51.67$ & $5.33+12.92=21.25$ \\
(ie, GIS $<94 \%)$ & 11.9 & $29 \%$ \\
\hline
\end{tabular}

Note: aParticipants with a maximum GIS (100\%) were exempted from out-of-pocket costs from July I, 2005.

Abbreviations: GIS, Guaranteed income supplement; CAD, Canadian dollars. 
selected in each household. In the event that more than one older adult was living in the household, the one with the closest birthday to the date of the call was recruited. The participation rate in the ESA survey was $76.5 \%$. The research project was reviewed and authorized by the ethics committee of the University Institute of Geriatrics of Sherbrooke.

\section{Data collection}

Briefly, the study included 2 face-to-face interviews separated by 1 year. The interviews were conducted by trained professionals in each participant's home and lasted, on average, 90 minutes. Each respondent received \$15 CAD as compensation. The Mini-Mental State Examination questionnaire was administered at the beginning of each interview. People who obtained a score of $<22$, indicating moderate-to-severe cognitive impairment, did not complete the full interview $(\mathrm{N}=27)$. Of the 2,784 participants who completed the ESA questionnaire (ESA-Q), 2,503 participants gave written informed consent allowing the research team to access their medical and pharmaceutical services files from the RAMQ database and their hospitalization services files from the "Maintenance et exploitation des données pour l'étude de la clientèle hôspitalière" (MED-ECHO) database for the year prior and the 2 years following the baseline interview. Using each participant's health insurance number, the self-reported data from ESA-Q were linked to the individual-level information from the RAMQ and MED-ECHO databases. Data were successfully matched for 2,494 individuals (99.6\%). Participants who were covered by a private drug insurance plan $(\mathrm{N}=208)$ were excluded because their pharmaceutical claims were not registered in the RAMQ drug registry database (Figures 1 and 2).

\section{Study sample}

The analytic sample for the present study included participants with a diagnosis of arterial hypertension, who were identified according to Canadian Chronic Disease Surveillance System criteria. ${ }^{2}$ Participants were considered hypertensive if

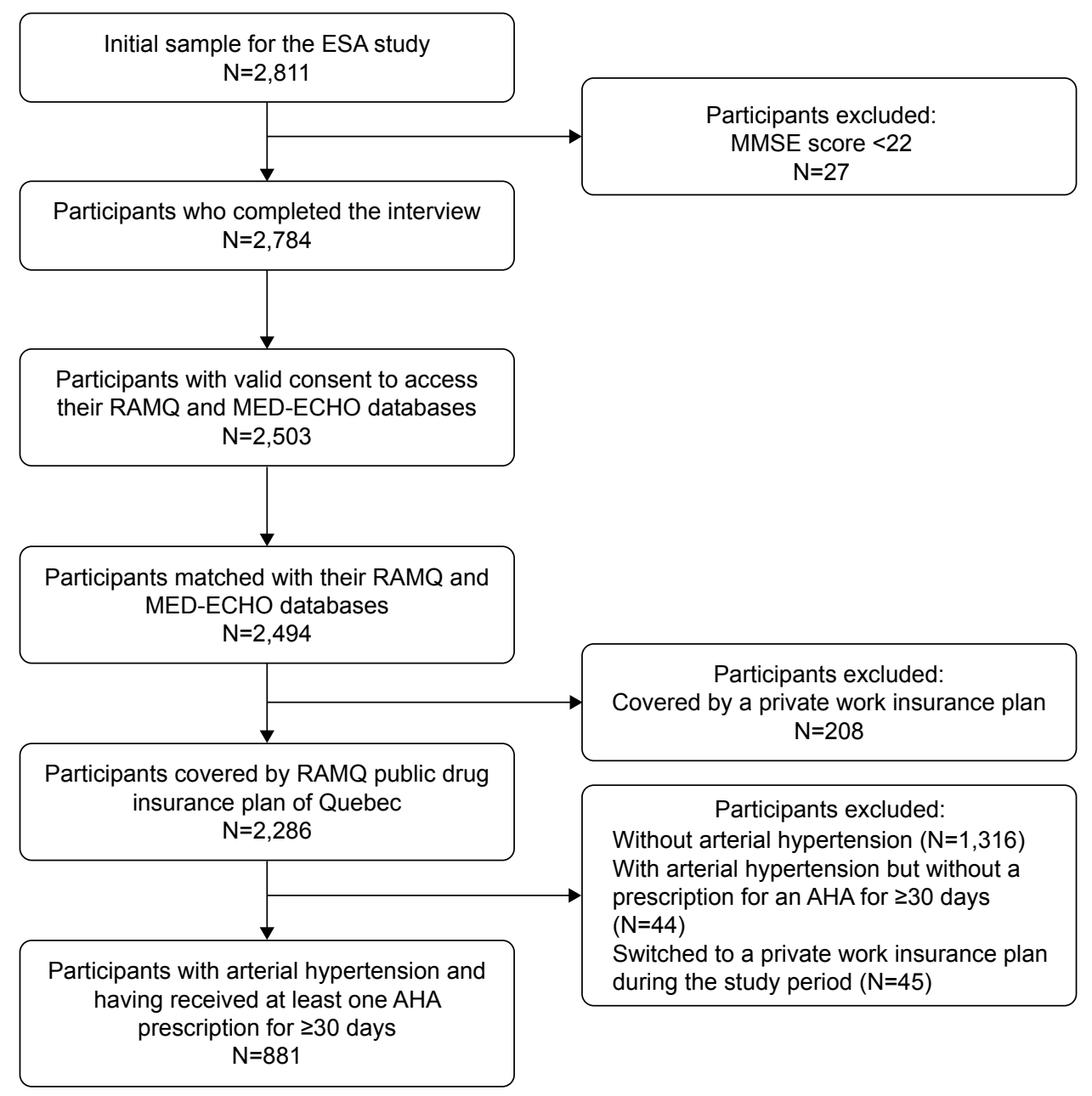

Figure I Study flow chart.

Abbreviations: AHA, antihypertensive agents; ESA, "Étude sur la santé des aînés"; MED-ECHO, “Maintenance et exploitation des données pour l'étude de la clientèle hôspitalière" [Database on hospitalizations]; MMSE, mini-mental state examination; RAMQ, "Régie de l'Assurance Maladie du Québec" [Quebec's medical insurance plan]. 


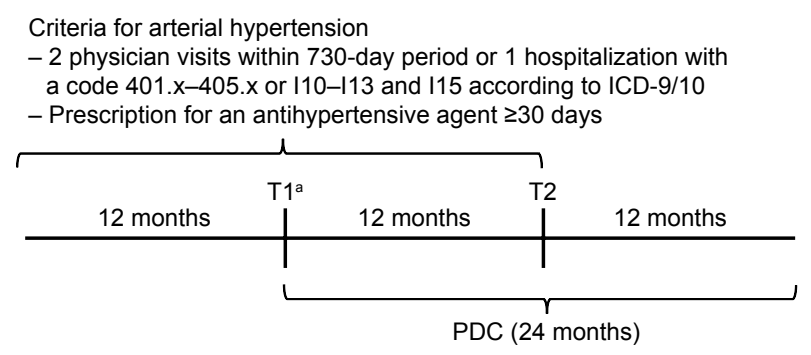

Figure 2 Time frame for data collection for each participant.

Note: ${ }^{a}$ The baseline interviews (TI) were conducted between February 27, 2005 and November 22, 2007. T2 represented as second interviews.

Abbreviations: ICD-9/10, International Classification of Diseases, 9th or 10th Edition; PDC, proportion of days covered.

they had within a 730-day period, in the RAMQ or in the MED-ECHO databases, at least 2 physician visits on 2 different days or 1 hospitalization with the following diagnostic codes: 401 .x to $405 . x$ or I1 10 to I13 and I1 5 conforming to the International Classification of Diseases, ninth or tenth edition (Figure 2). ${ }^{2}$ Participants who did not fill a prescription for an AHA for $\geq 30$ days were excluded ( $N=44)$. The classes of AHA identified in the study sample from the RAMQ drug registry database are listed in Table 2. Participants were also excluded from the study if they switched to a private insurance plan during the study period $(\mathrm{N}=45)$. The final sample for analysis included 881 participants with hypertension and treated with AHA (Figure 1).

\section{Dependent variable}

The main outcome measure of interest was adherence to AHA. It was measured using the proportion of days covered

Table 2 Classes of antihypertensive agents and comorbidities identified in the participants

\begin{tabular}{ll}
\hline $\begin{array}{l}\text { Classes of antihypertensive } \\
\text { agents identified in the } \\
\text { study sample using RAMQ } \\
\text { database }\end{array}$ & $\begin{array}{l}\text { Comorbidities that } \\
\text { were self-reported } \\
\text { during the ESA study } \\
\text { by the participants }\end{array}$ \\
\hline Alpha-adrenergic blockers & Anemia \\
ACEi & Eye diseases \\
ARB & Gastrointestinal diseases \\
Beta-adrenergic blockers & Hypercholesterolemia \\
Calcium channel blockers & Metabolism diseases \\
Direct vasodilators & Rheumatoid arthritis \\
Nitrates and nitrites & Serious back pain or \\
Combination pills: ACEi/ & pain in the spine \\
ACEi, ACEi/beta-adrenergic & Thyroid diseases \\
blockers, ACEi/ARB & Type Il diabetes \\
& Other cardiovascular \\
& diseases \\
\hline
\end{tabular}

Abbreviations: ACEi, angiotensin converting enzyme inhibitors; ARB, angiotensin II receptor antagonists; ESA, "Étude sur la santé des aînés”; RAMQ, "Régie de l'Assurance Maladie du Québec" [Quebec's medical insurance plan].
(PDC), which is the preferred measure when adherence is computed from pharmacy administrative claims databases. ${ }^{32,33}$ The PDC is defined as the total number of days supplied of a medication divided by the number of days in the observation period, regardless of the number of medications taken on the same day. Medication switches were also considered in the analysis. PDC was computed over a 2-year follow-up period (Figure 2). It was then categorized into a dichotomous variable: $<80 \%$ and $\geq 80 \%$. Participants with a PDC $\geq 80 \%$ were considered adherent.

\section{Independent variables}

The main independent variable of interest was the amount of out-of-pocket costs, based on information from the RAMQ drug registry database, which included the deductible and coinsurance rates for drugs dispensed and paid by beneficiaries. For each participant, only the first contribution paid for an AHA prescription at cohort entry was considered in the analysis. ${ }^{20}$ Out-of-pocket costs were then categorized as follows: $\$ 0 \mathrm{CAD}, \$ 0.01-\$ 5.00$ CAD, \$5.01-\$10.00 CAD, \$10.01-\$15.00 CAD and $\$ 15.01-\$ 36.00 \mathrm{CAD}$. The number of AHA (1 or $\geq 2)$ and total number of medications per prescription (continuous variable) dispensed at cohort entry were also retained from the RAMQ drug registry database.

The annual household income was self-reported during the interview ( $<\$ 15,000 \mathrm{CAD}$ or $\geq \$ 15,000 \mathrm{CAD}$ ). There were 87 missing data for annual household income. Missing data were classified according to the GIS. ${ }^{30}$ Participants with a GIS between $94 \%$ and $100 \%$ were considered to have an annual household income of $\angle \$ 15,000 \mathrm{CAD}(\mathrm{N}=1)$ and those with a GIS $<94 \%$ were considered in the $\geq \$ 15,000 \mathrm{CAD}$ income group ( $\mathrm{N}=86)$. Other study variables obtained during the at-home interview with the structured ESA-Q included the following: sex (male vs female), age (65-74 vs $\geq 75$ years), marital status (married/living as a couple vs single/divorced/ separated/widowed), region (metropolitan, urban or rural) and years of education ( $<10 \mathrm{vs} \geq 10$ years). The presence of depression and/or anxiety (yes or no) was also measured during the at-home interview with ESA-Q mental health module that was based on Diagnostic and Statistical Manual of Mental Disorders, Fourth Edition criteria. The number of physical chronic conditions (continuous variable) was also captured from a list of 18 diseases included in the questionnaire and the 10 diseases reported by the participants are presented in Table 2. The total length of inpatient stays (continuous variable) was retained from the MED-ECHO hospitalization registry database. 


\section{Statistical analysis}

Patient characteristics were summarized using proportions (\%) for categorical variables and medians (range: minimum and maximum) for continuous variables identified as not normally distributed with the non-parametric KolmogorovSmirnov test $(P=0.000)$. Bivariate and multivariable logistic regressions were used to evaluate the effect of out-of-pocket costs on adherence to AHA, while adjusting for all potentially confounding variables. Since the amount of out-of-pocket costs depends on the GIS that is based on the annual household income, a stratification by annual household income reported by the participants $(<\$ 15,000 \mathrm{CAD}$ vs $\geq \$ 15,000$ CAD) was also carried out. Unadjusted and adjusted odds ratios with $95 \%$ CI were reported. To ensure that our sample reflected the proportion of older adults across the geographic area in Quebec, data were weighted based on the following: 1) the probability of selection of the administrative region in the geographical area $(\pi[\mathrm{a}]) ; 2$ ) the conditional probability of selection of the household in the administrative region $(\pi[\mathrm{b} / \mathrm{a}])$; and 3 ) the conditional probability of selection of the subject in the household $(\pi[\mathrm{c} / \mathrm{ab}])$. The weight $(\mathrm{w})$ attributed to each subject represented the inverse of its probability of selection $(1 /[\pi\{a b c\}])$. The weighted sample included 2,798 older adults living at home. The mean and median sampling design effects were 0.94 and 0.95 . The statistical software package SPSS 22.0 was used for analyses.

\section{Results}

The demographic, socio-economic and clinical characteristics of the participants in this study are presented in Table 3. As seen, $80.8 \%$ of participants with arterial hypertension had a $\mathrm{PDC} \geq 80 \%$ during the 2-year follow-up period. The results did not show a difference between adherence groups ( $\mathrm{PDC}<80 \%$ and $\geq 80 \%$ ) with respect to age, sex, marital status, region, education, annual household income, out-of-pocket costs, presence of depression and/ or anxiety, number of self-reported comorbidities and total length of inpatient stays. Respondents with a PDC $<80 \%$ and $\geq 80 \%$ differed with respect to the number of AHA and total number of medications per prescription at cohort entry ( $P=0.009$ and $P=0.031$, respectively).

Overall bivariate and multivariable analyses are presented in Table 4. In the multivariable analysis, participants with a contribution of $\$ 5.01-\$ 10.00 \mathrm{CAD}(\mathrm{OR}=0.467$, 95\% CI: $0.220-0.989, P=0.047)$ and $\$ 10.01-\$ 15.00 \mathrm{CAD}$ (OR $=0.469,95 \% \mathrm{CI}: 0.221-0.998, P=0.049)$ were significantly less likely to be adherent to their AHA when compared with those with no contribution (\$0 CAD). Those with the
Table 3 Participants' characteristics by adherence to antihypertensive agents $(\mathrm{N}=88 \mathrm{I})$

\begin{tabular}{|c|c|c|c|}
\hline Characteristics & $\begin{array}{l}\text { PDC }<80 \%, \\
N=169 \\
(19.2 \%)\end{array}$ & $\begin{array}{l}\text { PDC } \geq 80 \%, \\
N=712 \\
(80.8 \%)\end{array}$ & $P$-value \\
\hline \multicolumn{4}{|l|}{ Sex, N (\%) } \\
\hline Male & $55(32.7)$ & $267(37.5)$ & 0.229 \\
\hline Female & II4 (67.3) & $445(62.5)$ & \\
\hline \multicolumn{4}{|l|}{ Age (years), N (\%) } \\
\hline $65-74$ & $88(52.2)$ & $378(53.1)$ & 0.799 \\
\hline$\geq 75$ & $81(47.8)$ & $334(46.9)$ & \\
\hline \multicolumn{4}{|l|}{ Region, N (\%) } \\
\hline Rural & $53(31.4)$ & $259(36.3)$ & 0.477 \\
\hline Urban & $31(18.3)$ & $112(15.8)$ & \\
\hline Metropolitan & $85(50.3)$ & $34 I(47.9)$ & \\
\hline \multicolumn{4}{|l|}{ Marital status, N (\%) } \\
\hline Married/living as a couple & $73(43.1)$ & $316(44.4)$ & 0.780 \\
\hline $\begin{array}{l}\text { Single/divorced/separated/ } \\
\text { widowed }\end{array}$ & $96(56.9)$ & $396(55.6)$ & \\
\hline \multicolumn{4}{|l|}{ Education (years), N (\%) } \\
\hline$<10$ & $47(28)$ & $168(23.6)$ & $0.25 \mathrm{I}$ \\
\hline$\geq 10$ & $122(72)$ & $544(76.4)$ & \\
\hline \multicolumn{4}{|l|}{ Annual household income, $\mathrm{N}(\%)$} \\
\hline$<\$ 15,000 \mathrm{CAD}$ & $32(18.9)$ & $127(17.8)$ & 0.739 \\
\hline$\geq \$ 15,000 \mathrm{CAD}$ & $137(8 \mid .1)$ & $585(82.2)$ & \\
\hline \multicolumn{4}{|c|}{ Out-of-pocket costs for AHA at cohort entry, N (\%) } \\
\hline$\$ 0 \mathrm{CAD}$ & $12(7.1)$ & $88(12.4)$ & 0.077 \\
\hline$\$ 0.01-\$ 5.00 \mathrm{CAD}$ & $36(21.3)$ & $195(27.4)$ & \\
\hline$\$ 5.01-\$ 10.00 \mathrm{CAD}$ & $39(23.1)$ & $134(18.8)$ & \\
\hline$\$ 10.01-\$ 15.00 \mathrm{CAD}$ & $45(26.6)$ & $159(22.3)$ & \\
\hline$\$ 15.01-\$ 36.00 \mathrm{CAD}$ & $37(21.9)$ & $136(19.1)$ & \\
\hline \multicolumn{4}{|c|}{ Number of AHA per prescription at cohort entry, $\mathrm{N}(\%)$} \\
\hline 1 & I2I (7I.6) & $429(60.3)$ & 0.009 \\
\hline$\geq 2$ & $48(28.4)$ & $283(39.7)$ & \\
\hline $\begin{array}{l}\text { Total number of medications } \\
\text { per prescription at cohort } \\
\text { entry, median ( } \min , \max )\end{array}$ & $6(I, 18)$ & $6(1,26)$ & 0.031 \\
\hline \multicolumn{4}{|l|}{ Depression and/or anxiety, N (\%) } \\
\hline No & $123(72.8)$ & $559(78.6)$ & 0.119 \\
\hline Yes & $46(27.2)$ & $153(21.4)$ & \\
\hline $\begin{array}{l}\text { Number of comorbidities self- } \\
\text { reported, median (min, max) }\end{array}$ & $3(0,10)$ & $3(0,11)$ & 0.693 \\
\hline $\begin{array}{l}\text { Total length of inpatient stays } \\
\text { (days), median (min, max) }\end{array}$ & $0(0,27)$ & $0(0,116)$ & 0.635 \\
\hline
\end{tabular}

Notes: ${ }^{a} 87.4 \%$ of participants were not hospitalized during the study period. Significant results are in bold, $P$-value $<0.05$.

Abbreviations: AHA, antihypertensive agents; Min, minimum; Max, maximum; PDC, proportion of days covered; CAD, Canadian dollars.

largest amount of contribution, \$15.01-\$36.00 CAD, were also less likely to be adherent; however, this association did not reach statistical significance $(\mathrm{OR}=0.482,95 \% \mathrm{CI}$ : $0.220-1.056, P=0.068)$.

The stratified analyses by income are presented in Table 5. Among participants with an annual household income $<\$ 15,000 \mathrm{CAD}$, non-adherence was associated with out-of-pocket costs for AHA, however, only in those with a 
Table 4 Overall bivariate and multivariable logistic regressions for medication adherence during the 2-year follow-up period ( $\mathrm{N}=88 \mathrm{I})$

\begin{tabular}{|c|c|c|c|c|c|c|}
\hline \multirow[t]{2}{*}{ Characteristics } & \multicolumn{3}{|c|}{ Bivariate analysis $(\mathrm{N}=\mathbf{8 8} \mathrm{I})$} & \multicolumn{3}{|c|}{ Multivariable analysis $(\mathrm{N}=\mathbf{8 8} \mathrm{I})$} \\
\hline & OR & $95 \% \mathrm{Cl}$ & $P$-value & OR & $95 \% \mathrm{Cl}$ & $P$-value \\
\hline \multicolumn{7}{|l|}{ Sex } \\
\hline Male & & Reference & & & Reference & \\
\hline Female & 0.808 & $0.567-1.153$ & 0.240 & 0.793 & $0.539-1.169$ & 0.241 \\
\hline \multicolumn{7}{|l|}{ Age (years) } \\
\hline $65-74$ & & Reference & & & Reference & \\
\hline$\geq 75$ & 0.964 & $0.689-1.349$ & 0.840 & 0.920 & $0.645-1.312$ & 0.645 \\
\hline \multicolumn{7}{|l|}{ Region } \\
\hline Rural & & Reference & & & Reference & \\
\hline Urban & 0.763 & $0.465-1.25 \mid$ & 0.283 & 1.000 & $0.622-1.610$ & 0.999 \\
\hline Metropolitan & 0.841 & $0.577-1.227$ & 0.370 & 1.396 & $0.840-2.322$ & 0.198 \\
\hline \multicolumn{7}{|l|}{ Marital status } \\
\hline Married/living as a couple & & Reference & & & Reference & \\
\hline Single/divorced/separated/widowed & 0.950 & $0.678-1.333$ & 0.768 & 1.040 & $0.712-1.519$ & 0.839 \\
\hline \multicolumn{7}{|l|}{ Education (years) } \\
\hline$<10$ & & Reference & & & Reference & \\
\hline$\geq 10$ & 1.257 & $0.862-1.833$ & 0.236 & 1.423 & $0.950-2.131$ & 0.087 \\
\hline \multicolumn{7}{|l|}{ Annual household income } \\
\hline$<\$ 15,000 \mathrm{CAD}$ & & Reference & & & Reference & \\
\hline$\geq \$ 15,000 \mathrm{CAD}$ & 1.076 & $0.700-1.654$ & 0.738 & 1.060 & $0.654-1.718$ & 0.812 \\
\hline \multicolumn{7}{|c|}{ Out-of-pocket costs for AHA at cohort entry } \\
\hline$\$ 0 \mathrm{CAD}$ & & Reference & & & Reference & \\
\hline$\$ 0.01-\$ 5.00 \mathrm{CAD}$ & 0.708 & $0.348-1.439$ & 0.340 & 0.686 & $0.328-1.435$ & 0.317 \\
\hline$\$ 5.01-\$ 10.00 \mathrm{CAD}$ & 0.449 & $0.220-0.913$ & 0.027 & 0.467 & $0.220-0.989$ & 0.047 \\
\hline$\$ 10.01-\$ 15.00 \mathrm{CAD}$ & 0.446 & $0.223-0.895$ & 0.023 & 0.469 & $0.22 I-0.998$ & 0.049 \\
\hline$\$ 15.01-\$ 36.00 \mathrm{CAD}$ & 0.482 & $0.236-0.985$ & 0.045 & 0.482 & $0.220-1.056$ & 0.068 \\
\hline \multicolumn{7}{|c|}{ Number of AHA per prescription at cohort entry } \\
\hline I & & Reference & & & Reference & \\
\hline$\geq 2$ & 1.638 & $1.137-2.360$ & 0.008 & 1.443 & $0.964-2.160$ & 0.074 \\
\hline \multicolumn{7}{|l|}{ prescription at cohort entry } \\
\hline \multicolumn{7}{|l|}{ Depression and/or anxiety } \\
\hline No & & Reference & & & Reference & \\
\hline Yes & 0.735 & $0.501-1.079$ & 0.116 & 0.689 & $0.460-1.032$ & 0.071 \\
\hline Number of comorbidities self-reported & 1.070 & $0.976-1.174$ & 0.149 & 1.041 & $0.933-1.162$ & 0.468 \\
\hline Total length of inpatient stays & 1.025 & $0.988-1.063$ & 0.190 & 1.026 & $0.986-1.067$ & 0.207 \\
\hline
\end{tabular}

Note: Significant results are in bold, $P$-value $<0.05$.

Abbreviations: AHA, antihypertensive agents; CAD, Canadian dollars.

contribution of $\$ 10.01-\$ 15.00 \mathrm{CAD}(\mathrm{OR}=0.175,95 \% \mathrm{CI}$ : $0.042-0.740, P=0.018$ ) as opposed to no contribution. Further to this, adherence to AHA decreased with every one medication added to the prescription $(\mathrm{OR}=0.864$, 95\% CI: $0.758-0.984, P=0.028$ ). In participants reporting an annual household income $\geq \$ 15,000 \mathrm{CAD}$, those with a contribution of $\$ 0.01-\$ 5.00$ CAD (OR $=0.194,95 \% \mathrm{CI}$ : $0.048-0.787, P=0.022), \$ 5.01-\$ 10.00 \mathrm{CAD}(\mathrm{OR}=0.146,95 \%$ CI: $0.036-0.589, P=0.007), \$ 10.01-\$ 15.00 \mathrm{CAD}(\mathrm{OR}=0.192$, 95\% CI: $0.047-0.777, P=0.021)$ and $\$ 15.01-\$ 36.00$ CAD (OR $=0.160,95 \%$ CI: $0.039-0.655, P=0.011$ ) were significantly less likely to be adherent to their AHA when compared with those with no contribution. We also found that participants who were treated with at least two AHA were more likely to be adherent to their medication than those being delivered only one AHA (OR $=1.735,95 \%$ CI: $1.085-2.775, P=0.021$ ).

\section{Discussion}

In this general population study of community-dwelling older adults with arterial hypertension, out-of-pocket costs as low as \$5 CAD for AHA were associated with close to a 2-fold decrease in adherence to AHA. This finding is consistent with other studies conducted previously in the USA and Canada that showed an association between out-of-pocket costs and adherence to AHA. ${ }^{15-20}$ A joint Canada-US population study found that residents in the USA were more likely to report cost-related barriers to adherence. ${ }^{21}$ It should be 
Table 5 Multivariable logistic regressions by annual household income, for medication adherence during the 2-year follow-up period

\begin{tabular}{|c|c|c|c|c|c|c|}
\hline \multirow[t]{2}{*}{ Characteristics } & \multicolumn{3}{|c|}{$\begin{array}{l}\text { Household income }<\$ 15,000 \text { CAD } \\
(\mathrm{N}=159)\end{array}$} & \multicolumn{3}{|c|}{$\begin{array}{l}\text { Household income } \geq \$ 15,000 \text { CAD } \\
(\mathrm{N}=722)\end{array}$} \\
\hline & OR & $95 \% \mathrm{Cl}$ & $P$-value & OR & $95 \% \mathrm{Cl}$ & $P$-value \\
\hline \multicolumn{7}{|l|}{ Sex } \\
\hline Male & & Reference & & & Reference & \\
\hline Female & 0.517 & $0.124-2.148$ & 0.364 & 0.840 & $0.555-1.273$ & 0.412 \\
\hline \multicolumn{7}{|l|}{ Age (years) } \\
\hline $65-74$ & & Reference & & & Reference & \\
\hline$\geq 75$ & 1.660 & $0.682-4.039$ & 0.264 & 0.822 & $0.549-1.230$ & 0.340 \\
\hline \multicolumn{7}{|l|}{ Region } \\
\hline Rural & & Reference & & & Reference & \\
\hline Urban & 1.145 & $0.320-4.094$ & 0.835 & 0.937 & $0.552-1.593$ & $0.8 \mathrm{II}$ \\
\hline Metropolitan & 1.765 & $0.469-6.644$ & 0.401 & 1.335 & $0.758-2.349$ & 0.317 \\
\hline \multicolumn{7}{|l|}{ Marital status } \\
\hline Married/living as a couple & & Reference & & & Reference & \\
\hline Single/divorced/separated/widowed & 1.240 & $0.279-5.508$ & 0.777 & 1.021 & $0.683-1.526$ & 0.921 \\
\hline \multicolumn{7}{|l|}{ Education (years) } \\
\hline$<10$ & & Reference & & & Reference & \\
\hline$\geq 10$ & 2.010 & $0.839-4.813$ & 0.117 & 1.248 & $0.775-2.011$ & 0.362 \\
\hline \multicolumn{7}{|c|}{ Out-of-pocket costs for AHA at cohort entry } \\
\hline$\$ 0 \mathrm{CAD}$ & & Reference & & & Reference & \\
\hline$\$ 0.01-\$ 5.00 \mathrm{CAD}$ & 1.218 & $0.349-4.25$ I & 0.757 & 0.194 & $0.048-0.787$ & 0.022 \\
\hline$\$ 5.01-\$ 10.00 \mathrm{CAD}$ & 0.797 & $0.182-3.489$ & 0.763 & 0.146 & $0.036-0.589$ & 0.007 \\
\hline$\$ 10.01-\$ 15.00 \mathrm{CAD}$ & 0.175 & $0.042-0.740$ & 0.018 & 0.192 & $0.047-0.777$ & 0.021 \\
\hline$\$ 15.01-\$ 36.00 \mathrm{CAD}$ & 1.159 & $0.207-6.491$ & 0.866 & 0.160 & $0.039-0.655$ & 0.011 \\
\hline \multicolumn{7}{|c|}{ Number of AHA per prescription at cohort entry } \\
\hline 1 & & Reference & & & Reference & \\
\hline$\geq 2$ & 0.771 & $0.307-1.934$ & 0.579 & 1.735 & $1.085-2.775$ & 0.021 \\
\hline $\begin{array}{l}\text { Total number of medications per } \\
\text { prescription at cohort entry }\end{array}$ & 0.864 & $0.758-0.984$ & 0.028 & 1.069 & $0.993-1.15 \mid$ & 0.075 \\
\hline \multicolumn{7}{|l|}{ Depression and/or anxiety } \\
\hline No & & Reference & & & Reference & \\
\hline Yes & 1.093 & $0.404-2.953$ & 0.861 & 0.657 & $0.4|4-1.04|$ & 0.074 \\
\hline Number of comorbidities self-reported & 1.153 & $0.907-1.467$ & 0.245 & 1.000 & $0.882-1.133$ & 0.997 \\
\hline Total length of inpatient stays & 1.009 & $0.949-1.073$ & 0.775 & 1.038 & $0.968-1.09 \mid$ & 0.153 \\
\hline
\end{tabular}

Note: Significant results are in bold, $P$-value $<0.05$.

Abbreviations: AHA, antihypertensive agents; CAD, Canadian dollars.

noted that policies on drug coverage in the USA are different from Canada. ${ }^{21,25-29}$ In the USA, older adults are eligible for Medicare part D, a health and drugs insurance program administered by the government. However, in the USA, there is a limit for drug coverage. After reaching a certain threshold, the patient enters a coverage gap (donut hole) and the drug beneficiary pays for the entire price of the drug. ${ }^{27}$ This is contrary to the drug policy plan in Quebec, where drug beneficiaries receive their medications free of charge after reaching a yearly maximum contribution. ${ }^{26,30}$

The results of this study also showed that among participants with a reported annual income $\geq \$ 15,000 \mathrm{CAD}$, those paying any amount of out-of-pocket costs were significantly less likely to be adherent to their AHA than those with no contribution. Among respondents with a reported income $<\$ 15,000 \mathrm{CAD}$, with the exception of those with a contribution between $\$ 10.01$ and $\$ 15.00 \mathrm{CAD}$, there was no association between out-of-pocket costs and adherence. This observation can in part be explained by the disparities in the yearly maximum contribution for patients based on low and high incomes. Participants with an annual income $<\$ 15,000$ CAD were more likely to have a high GIS (94\%-100\%) and those with an income $\geq \$ 15,000 \mathrm{CAD}$ were more likely to have a lower GIS. During the study period, the yearly maximum drug contribution for participants with a high GIS was \$200 CAD and for those with a lower GIS, the contribution varied between $\$ 560 \mathrm{CAD}$ and \$904 CAD. Furthermore, older adults with a maximum GIS have been exempted from out-of-pocket costs from July 1, 2005, and those with a GIS between $94 \%$ and $99 \%$ have been exempted from July $1,2007 .{ }^{30} \mathrm{We}$ can therefore hypothesize that participants reporting a lower income reached their annual maximum 
contribution faster and started receiving medications free of charge. This may explain the lack of a significant association between out-of-pocket costs and adherence in participants with a lower reported annual income. The reduced adherence associated with increased out-of-pocket costs in participants with an annual income $\geq \$ 15,000 \mathrm{CAD}$ may be explained in part by the higher threshold for the maximum annual drug contribution and to the fact that they were not exempted from paying out-of-pocket costs.

Of all the developed countries with a universal health care insurance program, Canada is the only country that does not provide a universal drug insurance program. ${ }^{23,28,34-37}$ Policies on public drug coverage plans vary across provinces ${ }^{23,28,34-37}$ and are based either on age, income or employment status. ${ }^{26,35}$ Private work-insurance drug plans also vary by province and third party payer. ${ }^{34,35}$ To date, Quebec is the only province where all residents are obligated to be covered either by the public or a private work drug insurance plan. ${ }^{28,34,35}$ A telephone survey across all provinces of Canada showed that Quebec residents reported the lowest rate of cost-related barriers to drug adherence. ${ }^{23}$ Nevertheless, according to our study, an increase in out-of-pocket costs for AHA was associated with non-adherence to AHA in Quebec senior residents with hypertension.

Although the implementation of a Pharmacare universal drug program in Canada has been previously discussed, its biggest challenge is the associated expenditures for the government. Recently, Morgan et al carried out a simulation to estimate the effects of adding universal drug coverage for essential medicines such as AHA. The authors estimated a reduction reaching $\$ 4.27$ billion $C A D$ per year for patients and private drug plans and an increase of $\$ 1.23$ billion CAD per year on drug costs for the government. ${ }^{37}$ These results suggest overall savings for society. Policies on drug coverage therefore should not be based on age, income or employment status, but on the clinical value of essential medications for chronic conditions. ${ }^{34,35}$ Like other developed countries with universal drug and health insurance programs, which includes the UK, New Zealand and the Netherlands, ${ }^{35}$ Canada should reduce or eliminate out-of-pocket costs for essential medicines to treat chronic conditions. ${ }^{35,37}$

Out-of-pocket costs for medications in Quebec are increasing and currently inlcude a monthly deductibe fee of $\$ 18.85 \mathrm{CAD}$ and a coinsurance of $34.5 \%$ in $2016-2017 .{ }^{30}$ A decrease in the amount of out-of-pocket costs for necessary medicines to treat chronic conditions and a decrease in the annual maximum contribution may help improve adherence to medication, thus reducing the inequity in access to medications among Quebec residents.
This study also showed that among participants reporting a higher income, those treated with more than one AHA were more likely to be adherent than those who were treated with one AHA. This finding is consistent with results from previous studies also reporting an increase in adherence with an increased number of AHA. ${ }^{38,39}$ Some have suggested that patients with a combination of AHA are better monitored by the health care professional, due to the higher risk of developing complications related to uncontrolled blood pressure, which, in turn, improves adherence. ${ }^{38-40}$ On the other hand, an increased number of medications per prescription in participants with lower income was associated with reduced adherence. Polypharmacy in lower socio-economic groups is a growing public health concern due to its negative influence on adherence. ${ }^{41-43}$

The results of this study should be interpreted in light of the following limitations. First, medication adherence was measured with information found in the RAMQ drug registry database that is based on dispensed prescriptions and not on actual consumption. This can lead to an overestimation of adherence rates. However, pharmacy claims databases are still considered a valid source to measure medication adherence. ${ }^{32,44-46}$ Second, the amount of out-ofpocket costs for medications has increased in the past decade for those with a GIS $<94 \%$. We can therefore assume that the percentage of participants with a larger amount of outpocket costs has also increased in the past 10 years and the results of this study, based on data from 2005 to 2008, may underestimate the association between out-of-pocket costs and adherence in the present context. Third, only the first out-of-pocket costs for an AHA prescription at cohort entry were considered and therefore if a participant switched to a more expensive class of AHA during the study period, this was not considered in the analysis. Finally, the study was conducted in a sample of older adults covered by a public health insurance plan and therefore the results cannot be generalized to older adults covered by private insurance plans or provinces with different policies on drug coverage and reimbursement. ${ }^{26,28}$

Despite these limitations, this study also has several strengths. This is the first study to assess the effect of out-ofpocket costs on adherence to AHA among older adults covered by the public health insurance plan in Quebec, during a 2-year follow-up period. The sample included both prevalent and incident users of AHA. Previous studies among patients with chronic conditions reported a decrease in adherence with time. ${ }^{46}$ Finally, data in this study also included linked selfreported measures from the at-home ESA survey to information found in the RAMQ and MED-ECHO databases, which 
increased the validity of results by controlling for various confounding variables and reducing the potential for recall bias regarding health care service and drug use.

\section{Conclusion}

The results of this study showed that drug beneficiary outof-pocket costs are associated with non-adherence to AHA among older adults covered by the public drug insurance plan in Quebec, more importantly in older adults reporting an annual household income of $\$ 15,000 \mathrm{CAD}$ and more. Future research on health and drug policies should focus on the effect of yearly maximum drug contributions paid by older adults with higher annual incomes. This may necessitate the revision of income thresholds to better reflect income purchasing power for health. Also, a decrease in out-of-pocket costs for essential medications to treat chronic conditions may help improve adherence. Future studies in Canada should focus on replicating these results for other chronic conditions in a larger sample and comparing adherence to treatment regimens in residents with different drug insurance plans.

\section{Acknowledgments}

The ESA study was supported by operating grants from the "Fonds de Recherche du Québec - Santé" (FRQS) (ref: 9854 and ref: 22251) and a Canadian Institutes of Health Research (CIHR) operating Grant (200683MOP).

\section{Disclosure}

HMV is a Senior research scholar with the FRQS. RM received a scholarship from the Faculty of Medicine and Health Sciences of Université de Sherbrooke. SGG holds a Doctoral Award - Frederick Banting and Charles Best Canada Graduate Scholarships (CGS-D) from CIHR (number: 146258). The authors report no other conflicts of interest in this work.

\section{References}

1. Statistics Canada. The 10 leading causes of death; 2011. Available from: http://www.statcan.gc.ca/pub/82-625-x/2014001/article/11896-eng.htm. Accessed February 9, 2017.

2. Public Health Agency of Canada. Report from the Canadian Chronic Disease Surveillance System: Hypertension in Canada; 2010. Available from: http://www.phac-aspc.gc.ca/cd-mc/cvd-mcv/ccdss-snsmc-2010/ pdf/CCDSS_HTN_Report_FINAL_EN_20100513.pdf. Accessed February 9, 2017.

3. Ho PM, Bryson CL, Rumsfeld JS. Medication adherence: its importance in cardiovascular outcomes. Circulation. 2009;119(23):3028-3035.

4. Padwal R, Straus SE, McAlister FA. Evidence based management of hypertension. Cardiovascular risk factors and their effects on the decision to treat hypertension: evidence based review. BMJ. 2001; 322(7292):977-980.
5. Savage PJ, Pressel SL, Curb JD, et al. Influence of long-term, low-dose, diuretic-based, antihypertensive therapy on glucose, lipid, uric acid, and potassium levels in older men and women with isolated systolic hypertension: The Systolic Hypertension in the Elderly Program. SHEP Cooperative Research Group. Arch Intern Med. 1998;158(7): 741-751.

6. Aronow WS, Fleg JL, Pepine CJ, et al. ACCF/AHA 2011 expert consensus document on hypertension in the elderly: a report of the American College of Cardiology Foundation Task Force on Clinical Expert Consensus documents developed in collaboration with the American Academy of Neurology, American Geriatrics Society, American Society for Preventive Cardiology, American Society of Hypertension, American Society of Nephrology, Association of Black Cardiologists, and European Society of Hypertension. J Am Coll Cardiol. 2011; 57(20):2037-2114.

7. Druss BG, Marcus SC, Olfson M, Tanielian T, Elinson L, Pincus HA. Comparing the national economic burden of five chronic conditions. Health Aff (Millwood). 2001;20(6):233-241.

8. Abegunde DO, Mathers CD, Adam T, Ortegon M, Strong K. The burden and costs of chronic diseases in low-income and middle-income countries. Lancet. 2007;370(9603):1929-1938.

9. Sokol MC, McGuigan KA, Verbrugge RR, Epstein RS. Impact of medication adherence on hospitalization risk and healthcare cost. Med Care. 2005;43(6):521-530.

10. Joffres MR, Campbell NR, Manns B, Tu K. Estimate of the benefits of a population-based reduction in dietary sodium additives on hypertension and its related health care costs in Canada. Can J Cardiol. 2007; 23(6):437-443.

11. Walker RL, Chen G, Campbell NR, et al. Canadian provincial trends in antihypertensive drug prescriptions between 1996 and 2006. Can J Cardiol. 2011;27(4):461-467.

12. Alhaddad IA, Hamoui O, Hammoudeh A, Mallat S. Treatment adherence and quality of life in patients on antihypertensive medications in a Middle Eastern population: adherence. Vasc Health Risk Manag. 2016;12:407-413.

13. Behnood-Rod A, Rabbanifar O, Pourzargar P, et al. Adherence to antihypertensive medications in Iranian Patients. Int J Hypertens. 2016;2016:1508752.

14. Tamblyn R, Laprise R, Hanley JA, et al. Adverse events associated with prescription drug cost-sharing among poor and elderly persons. JAMA. 2001;285(4):421-429.

15. Maciejewski ML, Bryson CL, Perkins M, et al. Increasing copayments and adherence to diabetes, hypertension, and hyperlipidemic medications. Am J Manag Care. 2010;16(1):e20-e34.

16. Taira DA, Wong KS, Frech-Tamas F, Chung RS. Copayment level and compliance with antihypertensive medication: analysis and policy implications for managed care. Am J Manag Care. 2006;12(11):678-683.

17. Kamal-Bahl S, Briesacher B. How do incentive-based formularies influence drug selection and spending for hypertension? Health Aff (Millwood). 2004;23(1):227-236.

18. Briesacher BA, Limcangco MR, Frech-Tamas F. New-user persistence with antihypertensives and prescription drug cost-sharing. J Clin Hypertens (Greenwich). 2007;9(11):831-836.

19. Yoon J, Ettner SL. Cost-sharing and adherence to antihypertensives for low and high adherers. Am J Manag Care. 2009;15(11):833-840.

20. Despres F, Forget A, Kettani FZ, Blais L. Impact of patient reimbursement timing and patient out-of-pocket expenses on medication adherence in patients covered by private drug insurance plans. J Manag Care Spec Pharm. 2016;22(5):539-547.

21. Kennedy J, Morgan S. A cross-national study of prescription nonadherence due to cost: data from the Joint Canada-United States Survey of Health. Clin Ther. 2006;28(8):1217-1224.

22. Tong X, Chu EK, Fang J, Wall HK, Ayala C. Nonadherence to antihypertensive medication among hypertensive adults in the United StatesHealthStyles, 2010. J Clin Hypertens (Greenwich). 2016;18(9):892-900.

23. Law MR, Cheng L, Dhalla IA, Heard D, Morgan SG. The effect of cost on adherence to prescription medications in Canada. CMAJ. 2012; 184(3):297-302. 
24. Kratzer J, Cheng L, Allin S, Law MR. The impact of private insurance coverage on prescription drug use in Ontario, Canada. Health Policy. 2015;10(4):62-74.

25. Hurley J, Morgan S. US Medicare reform: why drug companies and private insurers are smiling. CMAJ. 2004;170(4):461-462.

26. Health Canada. Provincial and territorial public drug benefit programs; 2017. Available from: http://www.hc-sc.gc.ca/hcs-sss/pharma/acces/ ptprog-eng.php. Accessed February 9, 2017.

27. Medicare. Medicare coverage (Part D). Available from: https://www. medicare.gov/part-d/index.html. Accessed March 13, 2017.

28. Kapur V, Basu K. Drug coverage in Canada: who is at risk? Health Policy. 2005;71(2):181-193.

29. Medicaid. Seniors \& Medicare and Medicaid Enrollees. Available from: https://www.medicaid.gov/medicaid/eligibility/medicaid-enrollees/ index.html. Accessed March 13, 2017.

30. Régie de l'assurance maladie du Québec. Le régime général d'assurance médicaments. Available from: https://www4.prod.ramq.gouv.qc.ca/ IST/CD/CDF_DifsnInfoStats/CDF1_CnsulInfoStatsCNC_iut/RappPDF.aspx?TypeImpression=pdf\&NomPdf=CC_AMHist_0000_0_O. pdf. Accessed February 9, 2017.

31. Régie de l'assurance maladie Du Québec. Rapport annuel de gestion: 2010-2011;2011. Available from: http:/www.ramq.gouv.qc.ca/SiteCollectionDocuments/citoyens/fr/rapports/rappann1011-fr.pdf. Accessed February 9, 2017.

32. Hess LM, Raebel MA, Conner DA, Malone DC. Measurement of adherence in pharmacy administrative databases: a proposal for standard definitions and preferred measures. Ann Pharmacother. 2006;40(7-8): 1280-1288.

33. Martin BC, Wiley-Exley EK, Richards S, Domino ME, Carey TS, Sleath BL. Contrasting measures of adherence with simple drug use, medication switching, and therapeutic duplication. Ann Pharmacother. 2009;43(1):36-44.

34. Daw JR, Morgan SG. Stitching the gaps in the Canadian public drug coverage patchwork?: a review of provincial pharmacare policy changes from 2000 to 2010. Health Policy. 2012;104(1):19-26.

35. Morgan SG, Daw JR, Law MR. Rethinking Pharmacare in Canada. 2013. C.D. Howe Institute Commentary 377. Available from: https:// www.cdhowe.org/sites/default/files/attachments/research_papers/ mixed/Commentary_384_0.pdf. Accessed February 9, 2017.
36. Morgan SG, Law M, Daw JR, Abraham L, Martin D. Estimated cost of universal public coverage of prescription drugs in Canada. CMAJ. 2015;187(7):491-497.

37. Morgan SG, Li W, Yau B, Persaud N. Estimated effects of adding universal public coverage of an essential medicines list to existing public drug plans in Canada. CMAJ. 2017;189(8):E295-E302.

38. Christe V, Waeber G, Vollenweider P, Marques-Vidal P. Antihypertensive drug treatment changes in the general population: the CoLaus study. BMC Pharmacol Toxicol. 2014;15:20.

39. Mazzaglia G, Mantovani LG, Sturkenboom MC, et al. Patterns of persistence with antihypertensive medications in newly diagnosed hypertensive patients in Italy: a retrospective cohort study in primary care. J Hypertens. 2005;23(11):2093-2100.

40. Leung AA, Nerenberg K, Daskalopoulou SS, et al. Hypertension Canada's 2016 Canadian Hypertension Education Program Guidelines for Blood Pressure Measurement, Diagnosis, Assessment of Risk, Prevention, and Treatment of Hypertension. Can J Cardiol. 2016;32(5): 569-588.

41. Odubanjo E, Bennett K, Feely J. Influence of socioeconomic status on the quality of prescribing in the elderly - a population based study. Br J Clin Pharmacol. 2004;58(5):496-502.

42. Maher RL, Hanlon J, Hajjar ER. Clinical consequences of polypharmacy in elderly. Expert Opin Drug Saf. 2014;13(1):57-65.

43. Kovacevic SV, Miljkovic B, Vucicevic K, et al. Elderly polypharmacy patients' needs and concerns regarding medication assessed using the structured patient-pharmacist consultation model. Patient Educ Couns. Epub 2017 May 1.

44. Osterberg L, Blaschke T. Adherence to medication. $N$ Engl J Med. 2005;353(5):487-497.

45. Grymonpre RE, Didur CD, Montgomery PR, Sitar DS. Pill count, selfreport, and pharmacy claims data to measure medication adherence in the elderly. Ann Pharmacother. 1998;32(7-8):749-754.

46. World Health Organization. Adherence to long-term therapies: evidence for action; 2003. Available from: http://apps.who.int/iris/bitstream/10 665/42682/1/9241545992.pdf. Accessed February 9, 2017.
Patient Preference and Adherence

\section{Publish your work in this journal}

Patient Preference and Adherence is an international, peer-reviewed, open access journal that focuses on the growing importance of patient preference and adherence throughout the therapeutic continuum. Patient satisfaction, acceptability, quality of life, compliance, persistence and their role in developing new therapeutic modalities and compounds to optimize

\section{Dovepress}

clinical outcomes for existing disease states are major areas of interest for the journal. This journal has been accepted for indexing on PubMed Central. The manuscript management system is completely online and includes a very quick and fair peer-review system, which is all easy to use. Visit http://www. dovepress.com/testimonials.php to read real quotes from published authors. 